\title{
Diurnal variation of gonadotropin levels in girls with early stages of puberty
}

\author{
Yu Sun Kang, MD', \\ Dong-Yoon Yoo, $\mathrm{MD}^{2}$, \\ In Hyuk Chung, MD', \\ Eun-Gyong Yoo, MD, PhD \\ ${ }^{1}$ Department of Pediatrics, CHA Gumi \\ Medical Center, CHA University, \\ Gumi, '2Department of Pediatrics, \\ CHA Bundang Medical Center, $\mathrm{CHA}$ \\ University, Seongnam, ${ }^{3}$ Department of \\ Pediatrics, National Health Insurance \\ Corporation Ilsan Hospital, Goyang, \\ Korea
}

Purpose: Pubertal gonadotropin secretion shows circadian pattern and the luteinizing hormone (LH) levels tend to rise in later stages of puberty in girls. We studied the usefulness of basal LH in the evaluation of central precocious puberty with emphasis on the influence of sampling time.

Methods: Medical records of 334 girls that underwent gonadotropin-releasing hormone stimulation test (GnRHST) were reviewed. Auxological and laboratory data were compared between those with early morning (EM, before $10 \mathrm{AM}$ ) and late morning/afternoon (LM/A, after $10 \mathrm{AM}$ ) basal samples.

Results: Among those in sexual maturity rating (SMR) 2, EM samples showed higher basal LH $(P=0.004)$ compare to LM/A samples, whereas those in SMR 3 showed no difference in $\mathrm{LH}$ levels between $\mathrm{EM}$ and LM/A samples. Among girls with pubertal response, EM group showed higher basal $\mathrm{LH}(P=0.031)$ and follicular stimulating hormone ( $P=0.008)$ than $\mathrm{LM} / \mathrm{A}$ group. The EM basal LH was more closely related with the peak stimulated LH than the LM/A basal LH did $\left(r_{s}=0.871\right.$ vs. $\left.r_{s}=0.524\right)$. The optimal basal LH cutoffs to predict a pubertal response to GnRHST were $0.11 \mathrm{IU} / \mathrm{L}$ with a sensitivity of $66.7 \%$ and a specificity of $78.7 \%$ in EM group, and $0.07 \mathrm{IU} / \mathrm{L}$ with a sensitivity of $60.0 \%$ and a specificity of $78.9 \%$ in LM/A group, respectively.

Conclusion: In girls with early stages of puberty, EM basal LH is a more sensitive screening tool than the LM/A basal LH. Diurnal variation should be considered in evaluating children with precocious puberty.

Keywords: Precocious puberty, Luteinizing hormone, Gonadotropin-releasing hormone

\section{Introduction}

Gonadotropin secretion at the onset of puberty shows marked circadian rhythm due to nocturnal gonadotropin secretion ${ }^{1)}$. The increase of plasma luteinizing hormone (LH) during sleep is initially seen in children at sexual maturity rating $(\mathrm{SMR}) 2-3^{2,3)}$. As puberty progresses, the daytime LH levels rise continuously until the diurnal rhythm is lost ${ }^{4,5)}$.

The early activation of hypothalamic-pituitary-gonadal (HPG) axis can result in central precocious puberty $(\mathrm{CPP})^{6}$. The standard method to confirm CPP is to measure the gonadotropin response to gonadotropin releasing hormone $(\mathrm{GnRH})$ administration ${ }^{7)}$. However, the GnRH stimulation test (GnRHST) is inconvenient to patients because of multiple blood sampling and cost. Several studies suggested that the serum basal LH level can be useful in the screening of girls with suspected $\mathrm{CPP}^{8-11)}$. However, because the circadian pattern of early pubertal gonadotropin secretion and the trend of serum LH levels to rise in later stages of puberty in girls, random daytime values of gonadotropins have limited usefulness in outpatient clinic setting. We studied the validity of basal LH for the screening of CPP in girls, with emphasis on the influence of sampling time.
Address for correspondence:

Eun-Gyong Yoo, MD, PhD

Department of Pediatrics, $\mathrm{CHA}$ Bundang Medical Center, $\mathrm{CHA}$ University, 59 Yatap-ro, Bundang-gu, Seongnam 13496, Korea

Tel: +82-31-780-1999

Fax: +82-31-780-5239

E-mail: pedyoo@cha.ac.kr

https://orcid.org/0000-0002-6452-

$655 X$
ISSN: 2287-1012(Print)

ISSN: 2287-1292(Online) 


\section{Materials and methods}

\section{Subjects}

Subjects were girls at 8 years of age or younger who visited the pediatric endocrinology clinic in Bundang CHA Medical Center due to precocious breast development and underwent the GnRHST between 2011 and 2014. After excluding those with peripheral precocious puberty or chronic illness, total 334 girls (240 girls in SMR 2, 91 girls in SMR 3, 3 girls in SMR 4 based on breast development) were included in the present study. This study was approved by the Institutional Review Board of CHA Bundang Medical Center (CHAMC 2016-09036-001). Written informed consent was obtained from all patients.

Participants were classified into early morning (EM) group when basal sampling before the administration of GnRH was performed before $10 \mathrm{AM}$, and children in whom the basal sampling was performed after $10 \mathrm{AM}$ was classified into late morning/afternoon (LM/A) group considering the circadian rhythm of gonadotropin ${ }^{11,12)}$. To compare the basal and stimulated gonadotropin levels between girls with similar stages of pubertal development, children were stratified by SMR and their response to GnRHST.

To compare the EM and LM/A data in the same patient, subgroup analysis was performed in 16 girls (all of whom were in SMR 2) who underwent GnRHST on different time range, within 4 weeks after initial basal sampling. In 12 girls, initial basal sampling was performed after 10 AM, and GnRHST including EM basal sample was performed before $10 \mathrm{AM}$, after $13.8 \pm 7.0$ days. Initial basal sampling was performed before 10 AM in 4 girls, followed by GnRHST including LM/A basal sample after 10 AM, after 10.0 \pm 6.2 days.

\section{Methods}

We reviewed the medical records of the subjects retrospectively. Clinical data at the time of GnRHST, such as chronological age, bone age, height, body weight, body mass index (BMI), SMR, parental height, and laboratory profiles, were collected. The standard deviation score (SDS) of the height, body weight and BMI were calculated using the 2007 Korean National Growth Charts $^{13)}$. Bone age was measured using the GreulichPyle method ${ }^{14)}$. Auxological and biochemical data were compared between EM and LM/A.

Basal serum samples for $\mathrm{LH}$, follicular stimulating hormone (FSH) and estradiol $\left(\mathrm{E}_{2}\right)$ were drawn immediately before the administration of $100 \mu \mathrm{g}$ of GnRH (Relefact LH-RH; SanofiAventis, Frankfurt, Germany). After injection, blood samples for LH and FSH were collected at 30, 45, and 60 minutes. Serum LH and FSH concentrations were measured using a chemiluminescence immunoassay (CLIA) (ADVIA Centaur XP Systems, Siemens, Germany). The sensitivity of the FSH and $\mathrm{LH}$ assays were $0.3 \mathrm{IU} / \mathrm{L}$ and $0.07 \mathrm{IU} / \mathrm{L}$, respectively. The percent coefficients of variation for replicate analysis were $<4 \%$ for both assays in the 0.3-200 IU/L for FSH and 0.07-200 IU/L for LH. $E_{2}$ was also measured by CLIA (UniCel DxI 800 system, Beckman Coulter, Brea, CA, USA). A peak stimulated LH concentration of $\geq 5.0 \mathrm{IU} / \mathrm{L}$ on the GnRHST was regarded as a pubertal response and $<5.0 \mathrm{IU} / \mathrm{L}$ was classified a prepubertal response ${ }^{10,15)}$.

\section{Statistical analysis}

All data were provided as the mean \pm standard deviation. Statistical analyses were performed by IBM SPSS Statistics ver. 21.0 (IBM Co., Armonk, NY, USA). Student $t$-test was used to compare values between the 2 groups. In subgroup analysis, Wilcoxon signed rank test was used to compare values and Spearman rank correlation was used to evaluate the relationships between basal serum LH and peak stimulated value. Multiple logistic regression models were fit with a pubertal response to GnRHST and BMI SDS, the basal gonadotropin value ( $\mathrm{LH}$ and $\mathrm{FSH})$ and $\mathrm{E}_{2}$.

Receiver operating characteristic (ROC) curves were constructed to evaluate the sensitivity and specificity at each level of LH based on predicted probability, and area under the curve (AUC) with 95\% confidence interval (CI) was measured for each curve. Youden's J index (sensitivity+specificity-1) was used to determine the optimal cut off point of basal serum $\mathrm{LH}$ from the ROC curve for each assay to differentiate girls with CPP from prepubertal girls ${ }^{16)}$. For these cutoff points, specificity and sensitivity were then recalculated to evaluate the cutoff point efficacy. $P$-value of $<0.05$ was considered statistically significant.

Table 1. Comparison of biochemical characteristics in subjects stratified by sexual maturity rating

\begin{tabular}{|c|c|c|c|c|}
\hline \multirow[b]{2}{*}{ Characteristic } & \multicolumn{2}{|c|}{ SMR 2} & \multicolumn{2}{|c|}{ SMR 3} \\
\hline & $\begin{array}{c}E M \\
(n=128)\end{array}$ & $\begin{array}{c}\mathrm{LM} / \mathrm{A} \\
(\mathrm{n}=112)\end{array}$ & $\begin{array}{c}E M \\
(n=53)\end{array}$ & $\begin{array}{l}\mathrm{LM} / \mathrm{A} \\
(\mathrm{n}=38)\end{array}$ \\
\hline Age (yr) & $7.7 \pm 0.5$ & $7.7 \pm 0.5$ & $7.8 \pm 0.4$ & $7.9 \pm 0.3$ \\
\hline Height SDS & $0.9 \pm 0.9$ & $0.8 \pm 0.9$ & $1.1 \pm 0.7$ & $1.0 \pm 0.7$ \\
\hline BMI SDS & $0.3 \pm 0.9$ & $0.3 \pm 0.9$ & $0.9 \pm 0.9^{*}$ & $0.3 \pm 0.9^{\dagger}$ \\
\hline BA-CA (yr) & $1.6 \pm 1.2$ & $1.4 \pm 0.7$ & $1.9 \pm 0.7$ & $1.8 \pm 0.7^{\ddagger}$ \\
\hline Basal LH (IU/L) & $0.32 \pm 0.56$ & $0.15 \pm 0.27^{*}$ & $0.42 \pm 0.65$ & $0.41 \pm 0.66^{\ddagger}$ \\
\hline Peak LH (IU/L) & $9.26 \pm 7.47$ & $10.41 \pm 8.62$ & $10.14 \pm 8.88$ & $12.78 \pm 9.29$ \\
\hline Basal FSH (IU/L) & $3.4 \pm 1.8$ & $2.8 \pm 1.2^{*}$ & $3.4 \pm 1.9$ & $3.3 \pm 2.2$ \\
\hline Peak FSH (IU/L) & $17.0 \pm 6.1$ & $16.7 \pm 5.3$ & $15.6 \pm 5.1$ & $15.6 \pm 4.6$ \\
\hline Basal LH/FSH & $0.07 \pm 0.10$ & $0.05 \pm 0.09$ & $0.09 \pm 0.12$ & $0.11 \pm 0.17$ \\
\hline Peak LH/FSH & $0.56 \pm 0.42$ & $0.61 \pm 0.46$ & $0.69 \pm 0.59$ & $0.86 \pm 0.68$ \\
\hline Estradiol (pg/mL) & $8.7 \pm 15.3$ & $6.0 \pm 13.9$ & $9.7 \pm 16.8$ & $6.3 \pm 12.4$ \\
\hline
\end{tabular}

Values are presented as mean \pm standard deviation.

$S M R$, sexual maturity rating; EM, early morning; LM/A, late morning/ afternoon; SDS, standard deviation score; BMI, body mass index; BACA, bone age-chronological age; LH, luteinizing hormone; FSH, follicular stimulating hormone.

${ }^{*} P<0.05$ vs. EM samples in SMR 2 group. ${ }^{\dagger} P<0.05$ vs. EM samples in SMR 3 group. ${ }^{\ddagger} P<0.05$ vs. LM/A samples in SMR 2 group. 


\section{Results}

\section{Characteristics of subjects stratified by SMR}

The descriptive statistics for auxological and biochemical data of participants stratified by SMR, and further divided by EM and LM/A groups are shown in Table 1. Whereas the differences of basal serum LH and FSH between EM and LM/A samples were significant in girls with SMR $2(P=0.004$ for LH and $P=0.001$ for FSH), there was no significant difference in basal LH and FSH levels between EM and LM/A samples in those with SMR 3 (Table 1). LM/A basal LH level in girls with SMR 3 was significantly higher than in those with SMR $2(P=0.040)$.

\section{Characteristics of subjects classified by response to GnRHST}

There was no significant difference in auxological data between prepubertal and pubertal response groups, except that prepubertal EM group showed higher BMI SDS compared to pubertal EM group $(P<0.001)$ (Table 2$)$. The basal and stimulated levels of gonadotropins in pubertal response group were higher than those of their prepubertal response counterparts (Table 2). In prepubertal response group, basal FSH in the EM group was higher than LM/A $(P=0.005)$. Among pubertal response group, the basal LH, FSH and $\mathrm{E}_{2}$ were significantly higher in the EM group than LM/A group $(P=0.031, P=0.008$,

Table 2. Comparison of auxological and biochemical characteristics in subjects classified by response to gonadotropin-releasing hormone stimulation test

\begin{tabular}{|c|c|c|c|c|}
\hline \multirow[b]{2}{*}{ Characteristic } & \multicolumn{2}{|c|}{ Prepubertal response } & \multicolumn{2}{|c|}{ Pubertal response } \\
\hline & $\begin{array}{c}E M \\
(n=61)\end{array}$ & $\begin{array}{l}\text { LM/A } \\
(n=39)\end{array}$ & $\begin{array}{c}E M \\
(n=120)\end{array}$ & $\begin{array}{c}\mathrm{LM} / \mathrm{A} \\
(\mathrm{n}=114)\end{array}$ \\
\hline$S M R, 2 / 3 / 4$ & $40 / 21 / 0$ & $31 / 8 / 0$ & $88 / 32 / 0$ & $81 / 30 / 3$ \\
\hline Age (yr) & $7.8 \pm 0.5$ & $7.7 \pm 0.5$ & $7.8 \pm 0.5$ & $7.7 \pm 0.4$ \\
\hline Height SDS & $1.1 \pm 0.8$ & & $0.9 \pm 0.9$ & $0.8 \pm 0.9$ \\
\hline BMI SDS & $0.9 \pm 0.9$ & $0.5 \pm 1.1$ & $0.3 \pm 0.9^{*}$ & $0.2 \pm 0.8$ \\
\hline Bone age (yr) & $9.4 \pm 0.8$ & $9.2 \pm 0.9$ & $9.5 \pm 0.9$ & $9.3 \pm 0.9$ \\
\hline $\mathrm{BA}-\mathrm{CA}(\mathrm{yr})$ & $1.7 \pm 0.7$ & $1.5 \pm 0.6$ & $1.7 \pm 1.2$ & $1.5 \pm 0.8$ \\
\hline Basal LH (IU/L) & $0.08 \pm 0.18$ & $0.05 \pm 0.10$ & $0.49 \pm 0.67^{*}$ & $0.31 \pm 0.50^{\dagger, \neq}$ \\
\hline Peak LH (IU/L) & $3.24 \pm 1.18$ & $3.00 \pm 1.22$ & $12.71 \pm 7.94^{*}$ & $14.00 \pm 8.56^{\dagger}$ \\
\hline Basal FSH (IU/L) & $2.5 \pm 1.2$ & $1.8 \pm 0.9^{*}$ & $3.9 \pm 1.9^{*}$ & $3.2 \pm 1.5^{\mathrm{t}, \mathrm{t}}$ \\
\hline Peak FSH (IU/L) & $15.0 \pm 4.2$ & $14.1 \pm 5.3$ & $17.4 \pm 6.4^{*}$ & $16.7 \pm 4.7^{\dagger}$ \\
\hline Basal LH/FSH & $0.02 \pm 0.04$ & $0.02 \pm 0.04$ & $0.11 \pm 0.12^{*}$ & $0.08 \pm 0.14^{\dagger}$ \\
\hline Peak LH/FSH & $0.23 \pm 0.11$ & $0.22 \pm 0.10$ & $0.79 \pm 0.48^{*}$ & $0.90 \pm 0.60^{\dagger}$ \\
\hline Estradiol (pg/mL) & $5.4 \pm 12.3$ & $8.8 \pm 19.5$ & $10.8 \pm 17.0^{*}$ & $6.1 \pm 12.1^{\ddagger}$ \\
\hline
\end{tabular}

Values are presented as mean \pm standard deviation.

SMR, sexual maturity rating; EM, early morning; LM/A, late morning/afternoon; SDS, standard deviation score; BMI, body mass index; BA-CA, bone age-chronological age; LH, luteinizing hormone; FSH, follicular stimulating hormone.

${ }^{*} P<0.05$ vs. EM samples in prepubertal response group. ${ }^{\dagger} P<0.05$ vs. LM/A samples in prepubertal response group. ${ }^{\ddagger} P<0.05$ vs. EM samples in pubertal response group. and $P=0.020$, for $\mathrm{LH}, \mathrm{FSH}$, and $\mathrm{E}_{2}$, respectively).

\section{Subgroup analysis to compare EM and LM/A data in the same patient}

A subgroup analysis was undertaken in 16 girls to compare the correlation between EM basal LH and peak LH vs. LM/A basal LH and peak LH. Subjects for subgroup analysis did not show significant difference in auxological data as compared with the total study group (age, $7.8 \pm 0.5$ years; height SDS, $0.9 \pm 0.9$; BMI SDS, $0.4 \pm 0.9$ ). Eleven girls $(69 \%)$ in the subgroup showed pubertal response to GnRHST. In the subgroup, EM samples showed significantly higher levels of basal serum LH $(0.51 \pm 0.60 \mathrm{IU} / \mathrm{L}$ vs. $0.18 \pm 0.18 \mathrm{IU} / \mathrm{L}, P=0.008), \mathrm{FSH}(3.8 \pm 1.9$ $\mathrm{IU} / \mathrm{L}$ vs. $2.7 \pm 1.1 \mathrm{IU} / \mathrm{L}, P=0.015)$ and $\mathrm{E}_{2}(8.6 \pm 14.2 \mathrm{pg} / \mathrm{mL}$ vs. $3.4 \pm 8.5 \mathrm{pg} / \mathrm{mL}, P=0.043$ ) levels than LM/A samples (Fig. 1). In Spearman correlation analysis, the EM basal LH was more

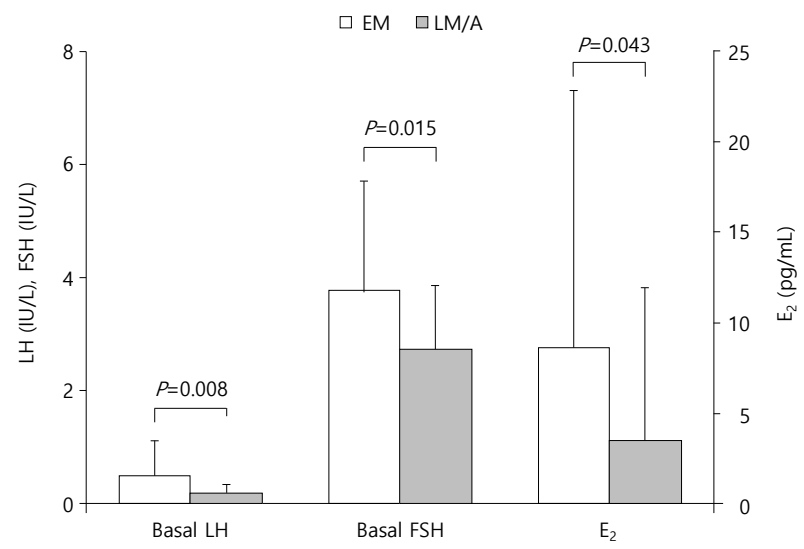

Fig. 1. Comparison of gonadotropin and estradiol levels in early morning (EM) vs. late morning/afternoon (LM/A) basal samples of the 16 girls in the subgroup analysis. LH, luteinizing hormone; $\mathrm{FSH}$, follicular stimulating hormone; $\mathrm{E}_{2,}$ estradiol.

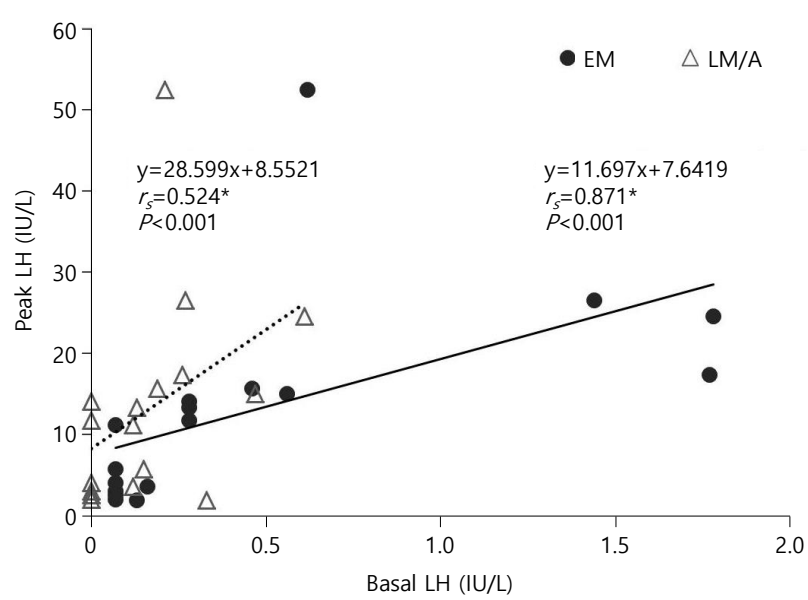

Fig. 2. Subgroup analysis showing correlations between basal LH and peak stimulated $L H$ in early morning (EM) vs. late morning/afternoon (LM/A) samples. $\mathrm{LH}$, luteinizing hormone; $\mathrm{FSH}$, follicular stimulating hormone. 
Table 3. Multiple logistic regression analysis of factors affecting the pubertal response of the gonadotropin-releasing hormone stimulation test

\begin{tabular}{|c|c|c|c|c|}
\hline Model & Variable & Coefficient ( $\beta$ ) & Standard error & $P$-value \\
\hline \multirow[t]{4}{*}{ EM model $\left(\mathrm{n}=181, R^{2}=0.195\right)$} & BMI SDS & -0.137 & 0.033 & $<0.001$ \\
\hline & Basal LH & 0.161 & 0.073 & 0.029 \\
\hline & Basal FSH & 0.054 & 0.023 & 0.021 \\
\hline & Estradiol & -0.002 & 0.002 & 0.437 \\
\hline \multirow[t]{4}{*}{ LM/A model $\left(n=153, R^{2}=0.157\right)$} & BMI SDS & -0.087 & 0.036 & 0.018 \\
\hline & Basal LH & 0.125 & 0.092 & 0.177 \\
\hline & Basal FSH & 0.087 & 0.025 & 0.001 \\
\hline & Estradiol & -0.004 & 0.002 & 0.069 \\
\hline
\end{tabular}

EM, early morning; LM/A, late morning/afternoon; BMI, body mass index; SDS, standard deviation score; LH, luteinizing hormone; FSH, follicular stimulating hormone.

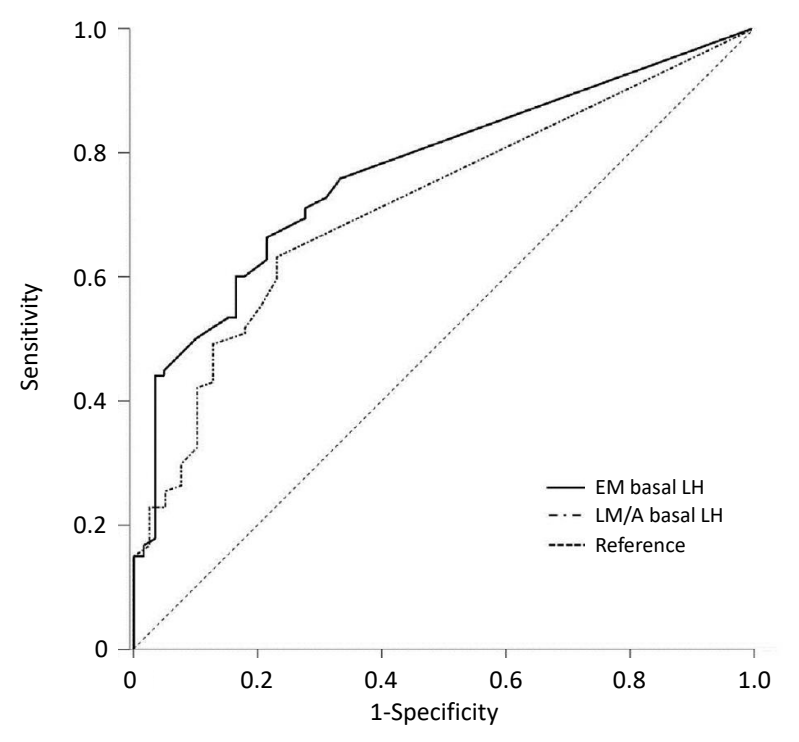

Fig. 3. Receiver operating characteristic curves for the optimal cutoff of basal serum LH levels for predicting pubertal response in early morning sample group (EM: area under the curve [AUC], 0.773; 95\% confidence interval [CI], 0.7040.841 ) and late morning/afternoon sample group (LM/A: AUC, 0.732; 95\% Cl, 0.641-0.823). EM, early morning; LM/A, late morning/afternoon; LH, luteinizing hormone.

closely related with peak LH level than the LM/A basal LH did $\left(r_{\mathrm{s}}=0.871\right.$ vs. $r_{\mathrm{s}}=0.524$; Fig. 2$)$.

\section{Regression analysis to define factors associated with pubertal response}

Multiple logistic regression analysis was undertaken to define factors associated with pubertal response to GnRHST in each group (Table 3). In EM group ( $\mathrm{n}=181)$, significant predictors of the pubertal response were higher basal LH $(P=0.029)$ and FSH $(P=0.021)$. BMI SDS was inversely associated with pubertal response to GnRHST in both groups $(P<0.001$ in EM group and $P=0.018$ in $\mathrm{LM} / \mathrm{A}$ group). In LM/A group $(\mathrm{n}=153)$, not basal LH, but basal FSH $(P<0.001)$ was the significant predictor of the pubertal response.

\section{ROC curve analysis to validate basal $\mathrm{LH}$ as a predictor of pubertal response}

ROC curves to verify the validity of basal LH as a predictor of pubertal response were constructed in each sample groups. In EM group, the AUC of basal LH was 0.773 (95\% CI, 0.704$0.841 ; P<0.001)$ and that in $\mathrm{LM} / \mathrm{A}$ group was $0.732(95 \% \mathrm{CI}$, $0.641-0.823 ; P<0.001$ ) (Fig. 3). The optimal cutoff value of basal LH related with a pubertal response was $0.11 \mathrm{IU} / \mathrm{L}$ in EM group. The sensitivity and specificity of basal $\mathrm{LH} \geq 0.11 \mathrm{IU} / \mathrm{L}$ in the EM group was $66.7 \%$ and $78.7 \%$, respectively. In LM/A group, the optimal basal LH cutoff was $0.07 \mathrm{IU} / \mathrm{L}$ and the sensitivity and specificity of this cutoff to predict a pubertal response was $61.7 \%$ and $76.5 \%$, respectively.

\section{Discussion}

A pulsatile LH secretory pattern during sleep, but not while the children are awake, is the first change in LH secretion at the early puberty ${ }^{2,3}$. Sleep associated LH release in the peripubertal period results from increased sensitivity of the pituitary gonadotropins to $\mathrm{GnRH}^{177}$. Third-generation assays demonstrate that $\mathrm{LH}$ increases during sleep to approach peaks in the lower adult range, above $1.0 \mathrm{U} / \mathrm{L}$, and then decrease during the day to $0.6 \mathrm{U} / \mathrm{L}$ or less in early puberty ${ }^{18,19)}$. Later on, a constant pulsatile secretion of LH during day and night occurs in pubertal children ${ }^{4,5)}$ and in adults ${ }^{20,211}$.

Boys at an early stage of puberty show that the timing in the changes of serum LH closely resembled that of FSH. In contrast, in girls, LH levels tend to rise in the later stages of puberty than that of $\mathrm{FSH}^{2223)}$. Therefore, girls in the early phase of HPG axis activation commonly do not show definite LH elevation in the afternoon. In our study, the basal levels of serum LH and FSH in the LM/A group were significantly lower than those in the EM group in girls with pubertal response to GnRHST. Especially, girls in SMR 2 showed significant difference in basal LH and FSH levels between EM and LM/A samples.

To perform the GnRHST for every patients with suspected $\mathrm{CPP}$ is relatively invasive and time-consuming. Among previous studies that evaluated the validity of basal serum LH levels 
for effective screening of CPP, some studies conducted blood sampling in the EM before $10 \mathrm{AM},{ }^{8,11)}$ and the others did not describe the time of blood sampling ${ }^{9,10)}$. Rosenfield et al. ${ }^{19)}$ suggested that sleep LH correlated with LH after stimulation of GnRHa across the pubertal transition. Our subgroup analysis suggested that basal serum LH in the EM is more strongly correlated with peak stimulated LH than that in the late morning or afternoon. Multiple regression analysis in our study showed that the basal LH level in the EM was a significant predictor of pubertal response whereas that in the late morning or afternoon samples was not.

The EM basal FSH level was significantly higher than LM/ A basal FSH independent of pubertal response, especially in girls with SMR 2 in the present study. It seems that the higher basal FSH level resulted in the increase of probability of a pubertal response to GnRHST in both EM an LM/A samples. The serum FSH level is higher than the LH level in prepubertal boys and girls ${ }^{24)}$. In girls, FSH levels rise during the early stages of puberty ${ }^{23)}$. Diurnal variation in serum FSH level is less than that of $\mathrm{LH}^{20)}$. Spontaneous FSH levels might provide more valuable data about pubertal status and more stable data with less prominent night-day variation. However, serum FSH levels rise about 2.5 fold, in contrast with $\mathrm{LH}$ levels increase of 25 fold or more over the course of puberty, and it results in overlapping between prepubertal and pubertal FSH levels ${ }^{10,25,26)}$ The response of $\mathrm{LH}$ to GnRH or GnRHa rises more than that of FSH during puberty ${ }^{25,27)}$. For these features, several studies suggested that the GnRH-stimulated FSH was not useful in diagnosing $\mathrm{CPP}^{10,11,26)}$. It was also demonstrated that basal $\mathrm{LH}$ levels were superior to $\mathrm{FSH}, \mathrm{E}_{2}$ and inhibin $\mathrm{B}$ to predict a response of GnRHST with comparison by ROC analyses ${ }^{9}$.

Accumulation of fat in the breast in overweight girls is difficult to be distinguished from breast development. Girls with high mean BMI $z$ scores had greater Tanner breast stage ${ }^{28)}$ and they may develop breasts without any specific evidence of HPG axis activation, suggesting a role of aromatized adrenal androgens ${ }^{29)}$. Several studies suggested that increased BMI is also correlated with earlier onset of puberty ${ }^{30,31)}$. However, it is not able to conduct a GnRHST to every overwight or obese girls with suspected breast development. For effective screening of these children, it is necessary to conduct blood sampling in consideration of diurnal variation. In addition, $\mathrm{Fu}$ et al. ${ }^{32)}$ suggested that BMI should be considered when interpreting GnRHST because higher BMI results in lower LH response to GnRHST. They suggested that decreased LH secretion in obese girl with CPP is related with elevated basal $\mathrm{E}_{2}$, insulin resistance and leptin level. Our results also showed the negative correlation between BMI and a pubertal response to GnRHST.

Several studies assessed the validity of using basal LH levels to evaluate girls with suspected CPP. Mogensen et al. ${ }^{9)}$ showed that an elevated basal LH was the significant predictor of a pubertal response for GnRHST. A basal LH level of $0.1 \mathrm{IU} /$ $\mathrm{L}$ by immunochemiluminometric assay, with a sensitivity of gondotropin assay of $0.02 \mathrm{IU} / \mathrm{L}$, was the optimal cutoff for discriminating CPP with a sensitivity of $94 \%$ of and a specificity of $88 \%{ }^{10)}$. Pasternak et al. ${ }^{11)}$ reported that a basal LH>0.1 IU/ L using CLIA with a sensitivity of LH assay of 0.05 IU/L was appropriate for the detection of CPP, and the sensitivity and specificity was $94.7 \%$ and $64.4 \%$, respectivrly. In Korea, Lee et al. ${ }^{8)}$ demonstrated that a basal $\mathrm{LH} \geq 0.1 \mathrm{IU} / \mathrm{L}$ can predict a pubertal reponse for GnRHST significantly, with a sensitivity of $56.4 \%$ and a specificity of $93.7 \%$. They measured LH using electrochemiluminescence immunoassay with limit of detection of $0.1 \mathrm{IU} / \mathrm{L}$. EM group in the present study showed the higher optimal cutoff value with the larger AUC than LM/ A group. Basal LH>0.11 IU/L was a diagnostic value with $66.7 \%$ of sensitiviy and $78.7 \%$ of specificity in the EM sample. LM/ A group showed $61.7 \%$ of sensitiviy and $76.5 \%$ of specificity with the cutoff level of $0.07 \mathrm{IU} / \mathrm{L}$. When the LH cutoff of 0.1 $\mathrm{IU} / \mathrm{L}$ was applied to our data in order to compare with the previous studies, the sensitivity and specificity were $70.0 \%$ and $72.1 \%$ in EM group and $51.1 \%$ and $82.4 \%$ in the LM/A group, respectively. Therefore, applying the same cutoff without considering sampling time or the detection limit of the test may result in different probability of predicting CPP. Most previous studies have not evaluated the diagnostic values considering diurnal fluctuation of LH levels. The present study showed that basal LH in the EM sample was more sensitive for screening CPP than in the late morning or afternoon sample. However, girls with basal LH under optimal cutoff in the late morning and afternoon still can not be excluded from precocious puberty, because up to $30 \%$ of them showed pubertal response in GnRHST in our study.

The present study has some limitaions. One of them is that the sensitivity of CLIA of gonadotropins in this study is lower than other studies using immunochemiluminometric assay, and the cutoff value was close from the detecton limit. Another limitation is that the subgroup analysis was conducted in a small subgroup and blood samples were taken on different days with 4-28 days of intervals, under the assumption that the change in gonadotropin levels in this population are insignificant in 4weeks. Further studies including a larger number of subjects with samples obtained on same day are required.

In conclusion, EM basal LH level is more sensitive than late morning or afternoon LH for the initial laboratory screening of girls in early stages of puberty. Diurnal variation should be considered in evaluating girls with precocious puberty, especially in those with early stages of puberty.

\section{Conflict of interest}

No potential conflict of interest relevant to this article was reported.

\section{References}

1. Oerter KE, Uriarte MM, Rose SR, Barnes KM, Cutler GB Jr. Gonadotropin secretory dynamics during puberty in normal girls and boys. J Clin Endocrinol Metab 
1990;71:1251-8.

2. Jakacki RI, Kelch RP, Sauder SE, Lloyd JS, Hopwood NJ, Marshall JC. Pulsatile secretion of luteinizing hormone in children. J Clin Endocrinol Metab 1982;55:453-8.

3. Kulin HE, Moore RG Jr, Santner SJ. Circadian rhythms in gonadotropin excretion in prepubertal and pubertal children. J Clin Endocrinol Metab 1976;42:770-3.

4. Corley KP, Valk TW, Kelch RP, Marshall JC. Estimation of GnRH pulse amplitude during pubertal development. Pediatr Res 1981;15:157-62.

5. Penny R, Olambiwonnu NO, Frasier SD. Episodic fluctuations of serum gonadotropins in pre- and post-pubertal girls and boys. J Clin Endocrinol Metab 1977;45:307-11.

6. Lee PA. Central precocious puberty. An overview of diagnosis, treatment, and outcome. Endocrinol Metab Clin North Am 1999;28:901-18, xi.

7. Brito VN, Batista MC, Borges MF, Latronico AC, Kohek $\mathrm{MB}$, Thirone AC, et al. Diagnostic value of fluorometric assays in the evaluation of precocious puberty. J Clin Endocrinol Metab 1999;84:3539-44.

8. Lee DS, Ryoo NY, Lee SH, Kim S, Kim JH. Basal luteinizing hormone and follicular stimulating hormone: is it sufficient for the diagnosis of precocious puberty in girls? Ann Pediatr Endocrinol Metab 2013;18:196-201.

9. Mogensen SS, Aksglaede L, Mouritsen A, Sørensen K, Main KM, Gideon P, et al. Diagnostic work-up of 449 consecutive girls who were referred to be evaluated for precocious puberty. J Clin Endocrinol Metab 2011;96:1393-401.

10. Neely EK, Wilson DM, Lee PA, Stene M, Hintz RL. Spontaneous serum gonadotropin concentrations in the evaluation of precocious puberty. J Pediatr 1995;127:47-52.

11. Pasternak Y, Friger M, Loewenthal N, Haim A, Hershkovitz E. The utility of basal serum LH in prediction of central precocious puberty in girls. Eur J Endocrinol 2012;166:295-9.

12. Boyar RM, Wu RH, Roffwarg H, Kapen S, Weitzman ED, Hellman L, et al. Human puberty: 24-hour estradiol in pubertal girls. J Clin Endocrinol Metab 1976;43:1418-21.

13. Moon JS, Lee SY, Nam CM, Choi JM, Choe BK, Seo JW, et al. 2007 Korean National Growth Charts: review of developmental process and an outlook. Korean J Pediatr 2008;51:1-25.

14. Greulich WW, Pyle SI. Radiologic atlas of skeletal development of the hand and wrist. 2nd ed. Standford (CA): Stanford University Press, 1959.

15. Carel JC, Eugster EA, Rogol A, Ghizzoni L, Palmert MR; ESPE-LWPES GnRH Analogs Consensus Conference Group, et al. Consensus statement on the use of gonadotropin-releasing hormone analogs in children. Pediatrics 2009;123:e752-62.

16. Schisterman EF, Perkins NJ, Liu A, Bondell H. Optimal cutpoint and its corresponding Youden Index to discriminate individuals using pooled blood samples. Epidemiology 2005;16:73-81.

17. Grumbach M, Kaplan S. The neuroendocrinology of human puberty: an ontogenetic perspective. In: Grumbach M, Sizonenko P, editors. Control of the onset of puberty II.
Baltimore: Williams and Wikins, 1990:1-68.

18. Mitamura R, Yano K, Suzuki N, Ito Y, Makita Y, Okuno A. Diurnal rhythms of luteinizing hormone, folliclestimulating hormone, testosterone, and estradiol secretion before the onset of female puberty in short children. J Clin Endocrinol Metab 2000;85:1074-80.

19. Rosenfield RL, Bordini B, Yu C. Comparison of detection of normal puberty in girls by a hormonal sleep test and a gonadotropin-releasing hormone agonist test. J Clin Endocrinol Metab 2013;98:1591-601.

20. Midgley AR Jr, Jaffe RB. Regulation of human gonadotropins. X. Episodic fluctuation of LH during the menstrual cycle. J Clin Endocrinol Metab 1971;33:962-9.

21. Nankin HR, Troen P. Repetitive luteinizing hormone elevations in serum of normal men. J Clin Endocrinol Metab 1971;33:558-60.

22. Apter D, Pakarinen A, Vihko R. Serum prolactin, FSH and LH during puberty in girls and boys. Acta Paediatr Scand 1978;67:417-23.

23. Grumbach M. Onset of puberty. In: Berenberg SR, editor. Puberty, biologic and social components. Leiden: H.E. Stenfert Kroese, 1975:1-21.

24. Kaplan SL, Grumbach MM, Aubert ML. The ontogenesis of pituitary hormones and hypothalamic factors in the human fetus: maturation of central nervous system regulation of anterior pituitary function. Recent Prog Horm Res 1976;32:161-243.

25. Apter D, Bützow TL, Laughlin GA, Yen SS. Gonadotropinreleasing hormone pulse generator activity during pubertal transition in girls: pulsatile and diurnal patterns of circulating gonadotropins. J Clin Endocrinol Metab 1993;76:940-9.

26. Schroor EJ, van Weissenbruch MM, Engelbregt M, Martens F, Meurs JM, Wennink JM, et al. Bioactivity of luteinizing hormone during normal puberty in girls and boys. Horm Res 1999;51:230-7.

27. Bordini B, Littlejohn E, Rosenfield RL. LH dynamics in overweight girls with premature adrenarche and slowly progressive sexual precocity. Int J Pediatr Endocrinol 2010;2010: Article ID 724696.

28. Kaplowitz PB. Link between body fat and the timing of puberty. Pediatrics 2008;121(3 Suppl):S208-17.

29. Shaw ND, Seminara SB, Welt CK, Au MG, Plummer L, Hughes VA, et al. Expanding the phenotype and genotype of female GnRH deficiency. J Clin Endocrinol Metab 2011;96:E566-76.

30. Davison KK, Susman EJ, Birch LL. Percent body fat at age 5 predicts earlier pubertal development among girls at age 9 . Pediatrics 2003;111(4 Pt 1):815-21.

31. Lee JM, Appugliese D, Kaciroti N, Corwyn RF, Bradley RH, Lumeng JC. Weight status in young girls and the onset of puberty. Pediatrics 2007;119:e624-30.

32. Fu JF, Liang JF, Zhou XL, Prasad HC, Jin JH, Dong GP, et al. Impact of BMI on gonadorelin-stimulated LH peak in premenarcheal girls with idiopathic central precocious puberty. Obesity (Silver Spring) 2015;23:637-43. 